\title{
Genetic monitoring detects an overlooked cryptic species and reveals the diversity and distribution of three invasive Rattus congeners in South Africa
}

\author{
Armanda D Bastos ${ }^{1,2^{*}}$, Deenadayalan Nair ${ }^{3}$, Peter J Taylor ${ }^{4}$, Helene Brettschneider ${ }^{1}$, Frikkie Kirsten ${ }^{5}$, \\ Elmarie Mostert ${ }^{1,2}$, Emil von Maltitz ${ }^{5}$, Jennifer M Lamb ${ }^{3}$, Pim van Hooft ${ }^{1,6}$, Steven R Belmain ${ }^{7}$, \\ Giancarlo Contrafatto ${ }^{3}$, Sarah Downs ${ }^{3}$, Christian T Chimimba ${ }^{1,2}$
}

\begin{abstract}
Background: South Africa's long and extensive trade activity has ensured ample opportunities for exotic species introduction. Whereas the rich biodiversity of endemic southern African fauna has been the focus of many studies, invasive vertebrates are generally overlooked despite potential impacts on biodiversity, health and agriculture. Genetic monitoring of commensal rodents in South Africa which uncovered the presence of Rattus tanezumi, a South-East Asian endemic not previously known to occur in Africa, provided the impetus for expanded studies on all invasive Rattus species present.

Results: To this end, intensified sampling at 28 South African localities and at one site in Swaziland, identified 149 Rattus specimens. Cytochrome $b$ gene sequencing revealed the presence of two $R$. tanezumi, seven Rattus rattus and five Rattus norvegicus haplotypes in south Africa. Phylogenetic results were consistent with a single, recent $R$. tanezumi introduction and indicated that $R$. norvegicus and $R$. rattus probably became established following at least two and three independent introductions, respectively. Intra- and inter-specific diversity was highest in informal human settlements, with all three species occurring at a single metropolitan township site. Rattus norvegicus and $R$. rattus each occurred sympatrically with Rattus tanezumi at one and five sites, respectively. Karyotyping of selected $R$. rattus and R. tanezumi individuals identified diploid numbers consistent with those reported previously for these cryptic species. Ordination of bioclimatic variables and MaxEnt ecological niche modelling confirmed that the bioclimatic niche occupied by $R$. tanezumi in south Africa was distinct from that occupied in its naturalised range in south-east Asia suggesting that factors other than climate may influence the distribution of this species.
\end{abstract}

Conclusions: This study has highlighted the value of genetic typing for detecting cryptic invasive species, providing historical insights into introductions and for directing future sampling. The apparent ease with which a cryptic species can become established signals the need for broader implementation of genetic monitoring programmes. In addition to providing baseline data and potentially identifying high-risk introduction routes, the predictive power of ecological niche modelling is enhanced when species records are genetically verified.

\section{Background}

The long and close association of members of the genus Rattus (Fischer de Waltheim) and Mus (Linnaeus) with humans have, primarily due to their high levels of adaptability and small size, made them two of the most successful invasive mammalian genera. Whilst the

\footnotetext{
* Correspondence: ADBastos@zoology.up.ac.za

'Mammal Research Institute, Department of Zoology and Entomology, University of Pretoria, Private Bag 20, Hatfield 0028, Pretoria, South Africa Full list of author information is available at the end of the article
}

negative impacts of commensal rodents, and Rattus in particular, on humans with respect to health and competition for food are undisputed [1], the positive contribution that some species have made as model/ experimental animals in biomedical research [2], and more recently towards tracing historical human migrations $[3,4]$, are increasingly acknowledged.

When introduced to areas outside their native range, the effects of invasive rodents on endemic biodiversity and on health can be detrimental, particularly in island

C Biomed Central

(c) 2011 Bastos et al; licensee BioMed Central Ltd. This is an Open Access article distributed under the terms of the Creative Commons Attribution License (http://creativecommons.org/licenses/by/2.0), which permits unrestricted use, distribution, and reproduction in any medium, provided the original work is properly cited. 
ecosystems. As reservoirs of a wide range of pathogens [5] capable of infecting diverse hosts, they have the potential to cause localised die-offs in native large mammal species [6] and in at least one extreme case, are believed to have precipitated the extinction of two endemic rats, $R$. macleari and $R$. nativitatus on Christmas island [7]. Their introduction to any ecosystem should, therefore, be carefully monitored to identify and address their presence and in so-doing, limit their impact. This hinges on early detection, which can be difficult particularly in the case of Rattus, a diverse genus containing numerous cryptic species. As a number of Rattus species have become successfully established outside their native range, this situation lends itself to a 'silent invasion' whereby a species can potentially go unnoticed for an extended period of time if its introduction was preceded by a cryptic species. This is partly because despite the substantive and undeniable impacts of invasive Rattus species, and their almost worldwide distribution, there is a lack of definitive morphological keys due to the paucity of studies on the taxonomy, origin and natural history of members of this globally-distributed invasive genus. A recent attempt to refine the higher-level taxonomy of the group and to base classifications within the Rattini tribe on a systematic approach that is firmly grounded in genetics [8] has highlighted the value of molecular phylogenetic approaches in addressing the intrinsic difficulties of this group of animals [1]. The study revealed the presence of at least seven discrete monophyletic lineages within the Indochinese Rattus rattus species complex, two more than predicted from traditional taxonomy, and also identified numerous examples of morphological misidentification [8]. In addition to delimiting species and resolving taxonomic relationships [8], molecular data permit estimations of the sequence and timing of species divergence. The generation of complete mitochondrial genome sequences of wild-caught species has provided more accurate estimations of the timing of divergences of five Rattus congeners [9], namely; the black rat, $R$. rattus (Linnaeus), the brown rat, $R$. norvegicus (Berkkenhaut), the Asian house rat, $R$. tanezumi (Temminck), the Polynesian rat, $R$. exulans (Peale) and the spiny rat, $R$. praetor (Thomas). Detailed intra-specific studies such as those performed on the Pacific rat, $R$. exulans, indicate that this species can be used as a proxy for studying pre-historic human migrations [10] and that $R$. rattus may similarly provide insights into more recent human migrations [4]. Despite its widespread occurrence, the available molecular and genetic data for $R$. norvegicus are primarily restricted to laboratory-adapted strains $[2,11]$ and data for wild-caught animals remains limited. Thus although invasive Rattus species are receiving increased attention, the complex taxonomy of the genus which is characterised by difficulties in morphology-based identifications, remains unclear $[1,12,13,8]$ and there is a paucity of data from areas invaded by members of this genus which comprises $c a$. 65 species. The availability of a comprehensive, homologous dataset from throughout the invaded and native ranges of each species would provide insights into the origins and dispersal routes of these economically important commensal species.

South Africa's rich biodiversity is exemplified by the approximately 50 murid rodent species which are known to occur in this country [14]. Only a small proportion of species, notably members of the genera Rattus, Mastomys, and Gerbilliscus (formerly Tatera; [15]), have been implicated in disease transmission $[16,17]$ and in causing damage to crops and stored grain [18]. The presence of cryptic species in South Africa and elsewhere $[19,20]$, complicates control and the value of molecular approaches for identifying morphologically indistinguishable murid rodents is increasingly being recognised $[21,13,8]$. This approach was applied in a European Commission and DFID-funded community participatory research programme undertaken in South Africa. It was during this routine molecular monitoring that the presence of $R$. tanezumi was discovered in South Africa [21,17], representing the first records of this species on the African continent. Before this, just two invasive Rattus species, $R$. norvegicus and $R$. rattus, were known to occur in South Africa [22]. The unexpected presence of a third Rattus species, which together with its sibling species, $R$. rattus forms part of the $R$. rattus species complex, provided the impetus for further sampling and genetic characterisation of rats from four provinces in South Africa, and forms the basis for this study, which aimed to determine the genetic diversity and geographic distribution of invasive, commensal Rattus species in South Africa. To this end, 149 Rattus specimens from South Africa and Swaziland were identified to species level on the basis of mitochondrial cytochrome $b$ (cyt $b$ )gene sequencing. Karyotyping of selected $R$. rattus and $R$. tanezumi individuals was performed to confirm the molecular identifications. Geographic distribution records for the native range of R. tanezumi (obtained from public domain museum databases provided by the Global Biodiversity Information Facility; http://www.gbif.org) were used to predict the distribution of this species in sub-Saharan Africa and to determine the factors that may influence its distribution.

\section{Methods}

\section{Species and sampling}

Two invasive Rattus species with markedly different geographical distributions occur in South Africa: $R$. norvegicus is reported to be a coastal-bound species and 
$R$. rattus as being widely distributed throughout the country [22]. A third, newly recorded species, $R$. tanezumi was identified from two sites in Limpopo Province [21] and from one site in KwaZulu-Natal Province [17]. The subsequent intensified sampling, confirmed Rattus species presence at two further Limpopo Province (LP) localities, at one site in Mpumalanga Province (MP), eight in Gauteng Province (GP), 15 in KwaZulu-Natal (KZN) Province and one site in Swaziland (summarised in Tables 1 and 2). In this study, 'south Africa' refers to the region that incorporates South Africa and the two landlocked countries of Lesotho and Swaziland.

Samples were obtained by snap-trapping and through routine extermination programmes conducted by pest control companies in townships and at facilities such as the O.R. Tambo International Airport. A small number of animals were live-trapped, using Sherman traps (H.B. Sherman Traps Inc. Florida, U.S.A.) baited with a mixture of peanut butter, oatmeal and fish oil. After capture, during transportation and in the laboratory, the live-trapped animals were kept in polyurethane cages with wood shavings provided as bedding, and mouse pellets and water provided ad libitum, as per the guidelines of the American Society of Mammalogists (ASM; http://www.mammalogy.org/committees/index.asp; Animal Care and Use Committee 1998). Animals were euthanized in accordance with the protocol approved by the Animal Ethics subcommittee of the University of KwaZulu-Natal Research Committee. Voucher specimens were prepared using standard natural history museum procedures for mammal specimens and are deposited in the South African mammal reference collections of the Transvaal Museum (TM) of the Northern Flagship Institute (NFI) in Pretoria and the Durban Natural Science Museum (Table 1).

\section{Cytochrome $b$ gene characterisation}

Total genomic DNA was extracted from either liver or kidney samples using the High Pure PCR template preparation kit (Roche) according to the prescribed manufacturer protocol. The entire cytochrome $b$ gene was amplified using murid rodent primers that bind within the mitochondrial genome regions flanking cyt $b$, namely L14724 TGAYATGAAAAAYCATCGTTG and H15915 CATTTCAGGTTTACAAGAC [20]. The thermal cycling profile consisted of two cycles of denaturation at $96^{\circ} \mathrm{C}$ for $12 \mathrm{~s}$, primer annealing at $52^{\circ} \mathrm{C}$ for $30 \mathrm{~s}$, and extension at $70^{\circ} \mathrm{C}$ for $60 \mathrm{~s}$. Keeping denaturation and extension steps the same, the next three cycles were performed at an annealing temperature $(\mathrm{Ta})$ of $50^{\circ} \mathrm{C}$, with the $\mathrm{Ta}$ of the final 35 cycles being adjusted to $48^{\circ} \mathrm{C}$. The resulting amplicon, approximately $1.2 \mathrm{~kb}$ in length, was purified directly from the tube using the High Pure PCR product purification kit (Roche) according to manufacturer specifications.
Nucleotide sequences were determined by cycle sequencing with either version 3.0 or 3.1 of the Big Dye Terminator Cycle Sequencing Ready Reaction kit (Applied Biosystems), at a Ta of $48^{\circ} \mathrm{C}$, with each of the PCR primers in separate reactions. Sequences were precipitated and run on the ABI PRISMTM 3100 Analyser (Applied Biosystems). Forward and reverse nucleotide sequences were viewed and aligned in Mega4 [23] and full-length cyt $b$ gene contigs, 1140 nucleotides (nt) in length, were generated for 147 southern African Rattus specimens and for three additional samples obtained from Indonesia and Vietnam (Table 1). Two partial sequences were also generated for $R$. rattus haplotypes RR10 and RR11 from KZN (Table 1). Of the 152 Rattus sequences generated, 143 were from Rattus sampled in South Africa (71 R. tanezumi, 35 R. rattus and $37 R$. norvegicus), six were from Swaziland and three from outside south Africa (Table 1). At least one sequence per species, locality and haplotype was submitted to Genbank http://www.ncbi.nlm.nih.gov under the accession numbers listed in Table 1.

\section{Molecular analyses}

The 150-taxon full-length Rattus cyt $b$ gene dataset generated in this study, and containing specimens from South Africa, Swaziland, Indonesia and Vietnam, was reduced to a dataset of 24 taxa which retained all of the sequence diversity on a per-species, per-province and per-haplotype basis. This dataset was complemented with 23 full-length cyt $b$ gene sequences containing 20 Rattus conspecific sequences available in the Genbank database (Table 1) and three Mus musculus outgroup sequences. The latter comprised two Genbank entries (accession numbers EF108343-4) and one M. m. domesticus haplotype identified in this study following nucleotide sequencing of two specimens from South Africa (accession number HQ157798). The best-fit model and parameters identified under the Akaike Information Criterion (AIC) in ModelTest 3.7 [24] guided model selection for the Minimum Evolution (ME) and Maximum Likelihood (ML) analyses performed in Mega4 [23] and PhyML [25], respectively, and for setting priors for Bayesian inference (BI) with MrBayes [26]. For the latter analyses, four Markov Monte Carlo chains were run for 10,000,000 generations using default heating and swap settings, and were sampled every 2000 generations, with $20 \%$ of the run being discarded as 'burn-in'. Three independent runs were performed to ensure convergence. Nodal support for clades was assessed by 100,000 and 1,000 non-parametric bootstrap replicates for $\mathrm{ME}$ and $\mathrm{ML}$, respectively, and from Bayesian posterior probabilities (BPP). In addition to inferring relationships from available full-length cyt $b$ sequences, partial cyt $b$ datasets (> $1000 \mathrm{bp}$ in length) were compiled for $R$. rattus and $R$. tanezumi which incorporated the haplotype 
Table 1 Summary of the cytochrome $b$ gene sequences generated in this study for the three invasive Rattus species occurring in South Africa and the reference sequences used for genetic analyses

\begin{tabular}{|c|c|c|c|c|}
\hline \multicolumn{5}{|c|}{ Rattus tanezumi (south Africa) } \\
\hline Haplotype & Sampling Locality & $\mathrm{N}$ & Genbank AN (Museum AN) & Reference \\
\hline RT01 & Giyani (Nkomo-B), LP & 7 & DQ439816- DQ439822 & This study \\
\hline RT01 & Tshilimbani, LP & 19 & HQ157805 & This study \\
\hline RT01 & Tholakele, Paulpietersburg, KZN & 2 & DQ439823, DQ439826 & This study \\
\hline RT01 & Mvuzini, Vryheid, KZN & 3 & DQ439824-5, DQ439827 & This study \\
\hline RT01 & Ophuzane, Paulpietersburg, KZN & 6 & DQ439829, DQ439845-8 & This study \\
\hline RT01 & Hammanskraal, GP & 12 & DQ439828 & This study \\
\hline RT01 & Rietondale, Pretoria, GP & 1 & DQ444864 & This study \\
\hline RT01 & Moreleta Park, Pretoria, GP & 1 & FJ842262 & This study \\
\hline RT01 & Tembisa, GP & 3 & HQ157804 & This study \\
\hline RT01 & Roodeplaat, GP & 13 & HQ157807 & This study \\
\hline RT01 & Richmond, KZN & 1 & FJ842263 (DM8685) & This study \\
\hline RT01 & Shongweni, Durban, KZN & 2 & DQ439849-50 (DM8401, DM8402) & This study \\
\hline RT01 & Swaziland (Mcaphozini Area) & 6 & FJ842264 (DM8892, DM8896-8900) & This study \\
\hline RT02 & Tembisa, GP & 1 & FJ842265 & This study \\
\hline 2 & 14 localities & 77 & & \\
\hline \multicolumn{5}{|c|}{ Rattus tanezumi (elsewhere) } \\
\hline Haplotype & Country (Locality) & $\mathrm{N}$ & Genbank AN (Museum AN) & Reference \\
\hline RT03 & Japan, Vietnam & 3 & AB355899-900, AB211040 & {$[29,30]$} \\
\hline RT04 & Japan (Amami Island) & 1 & EU273712 & {$[9]$} \\
\hline RT05 & Japan & 1 & AB211041 & {$[29]$} \\
\hline RT06 & Vietnam & 1 & AB355901 & {$[30]$} \\
\hline RT07 & China & 1 & AB096841 & {$[28]$} \\
\hline 5 & 3 countries & 7 & & \\
\hline \multicolumn{5}{|c|}{ Rattus rattus (South Africa) } \\
\hline Haplotype & Sampling Locality & $\mathrm{N}$ & Genbank AN (Museum AN) & Reference \\
\hline RR01 & Giyani (Nkomo-B), LP & 9 & DQ439830, DQ439851-8 & This study \\
\hline RR01 & Sekhukhune (Bloublommetjieskloof), LP & 2 & DQ439831-2 & This study \\
\hline RR01 & Tshilimbani, LP & 4 & HQ157802 & This study \\
\hline RR01 & Tembisa, GP & 1 & HQ157801 & This study \\
\hline RR03 & Hammanskraal, GP & 4 & DQ439834-5 & This study \\
\hline RR03 & Moreleta Park, Pretoria, GP & 1 & FJ842266 & This study \\
\hline RR03 & Tembisa, GP & 2 & HQ157800 & This study \\
\hline RRO3 & Verena, MP & 1 & HQ157803 & This study \\
\hline RR04 & Renosterkop, LP & 1 & HQ157806 & This study \\
\hline RR04 & Hammanskraal, GP & 1 & DQ439833 & This study \\
\hline RR04 & Hillcrest, Pretoria, GP & 1 & FJ842267 & This study \\
\hline RR04 & Umkomaas, KZN & 5 & DQ439836-8 (DM8403-7) & This study \\
\hline RR05 & Hammanskraal, GP & 1 & FJ842268 & This study \\
\hline RR06 & Cape Town, WCP & 2 & GQ891608 & {$[4]$} \\
\hline RR10 & Melmoth, KZN & 1 & [HQ157808] (DM8820) & This study \\
\hline RR11 & Ladysmith, KZN & 1 & [HQ157809] (DM8907) & This study \\
\hline 7 & 13 localities & 37 & & \\
\hline \multicolumn{5}{|c|}{ Rattus rattus (elsewhere) } \\
\hline Haplotype & Country (Locality) & $\mathrm{N}$ & Genbank AN & Reference \\
\hline RR01 & Tanzania & 1 & H217365 & {$[8]$} \\
\hline RR02 & Indonesia & 1 & AB033702 & {$[27]$} \\
\hline RR06 & New Zealand (Titirangi) & 1 & EU273707 & {$[9]$} \\
\hline RR07 & Japan & 2 & AB211039 [AB211042] & [29] \\
\hline RR08 & India & 1 & $\mathrm{H} 217367$ & {$[8]$} \\
\hline
\end{tabular}


Table 1 Summary of the cytochrome $b$ gene sequences generated in this study for the three invasive Rattus species occurring in South Africa and the reference sequences used for genetic analyses (Continued)

\begin{tabular}{|c|c|c|c|c|}
\hline RR09 & Oman & 1 & H217366 & {$[8]$} \\
\hline 6 & 6 countries & 7 & & \\
\hline \multicolumn{5}{|c|}{ Rattus norvegicus (South Africa) } \\
\hline Haplotype & Sampling Locality & $\mathrm{N}$ & Genbank AN (Museum AN) & Reference \\
\hline RNO1 & Sydenham, Durban, KZN & 2 & FJ842270 (DM7744, DM7745) & This study \\
\hline RN01 & Durban CBD, KZN & 3 & FJ842271 (DM7783, DM7804-5) & This study \\
\hline RN01 & Montclair Park, Durban, KZN & 2 & DQ439842-3 (DM7788, DM7789) & This study \\
\hline RN01 & Cato Crest IS, Durban, KZN & 2 & FJ842272 (DM7802, DM7803) & This study \\
\hline RN01 & Cato Manor Rd, Durban, KZN & 1 & DQ439844 (DM7820) & This study \\
\hline RN01 & Tembisa, GP & 1 & FJ842269 & This study \\
\hline RN01 & O.R. Tambo International Airport, GP & 1 & FJ842273 & This study \\
\hline RNO1 & Johannesburg Zoological Gardens & 8 & HQ157799 & This study \\
\hline RNO2 & Cato Crest IS, Durban, KZN & 2 & FJ842274 (DM7790, DM7791) & This study \\
\hline RNO3 & Durban Harbour, KZN & 2 & DQ439840-1 (DM7706, DM7711) & This study \\
\hline RNO4 & Warwick Ave, Durban, KZN & 1 & DQ439839 (DM7645) & This study \\
\hline $\mathrm{RN} 12$ & O.R. Tambo International Airport, GP & 9 & FJ842275 & This study \\
\hline RN12 & Tembisa, GP & 3 & FJ842276 & This study \\
\hline 5 & 10 localities & 37 & & \\
\hline \multicolumn{5}{|c|}{ Rattus norvegicus (elsewhere) } \\
\hline Haplotype & Sampling Locality of wild caught animals/(Lab Strain) & $\mathbf{N}$ & Genbank AN & Reference \\
\hline RN01 & (BN/SsNHsdMCW) & 1 & AY172581 & [46] \\
\hline RN01 & China*, Sweden & 2 & [GU592972*], FJ919765 & [11] \\
\hline RNO9 & (GH/OmrMcwi), [GH/Swe] & 2 & DQ673911, [DQ673913] & {$[2]$} \\
\hline RN10 & Milwaukee, USA & 1 & DQ673916 & [2] \\
\hline RN05 & Indonesia & 1 & FJ842279 & This study \\
\hline RN07 & Vietnam & 1 & FJ842278 & This study \\
\hline RN08 & Vietnam & 2 & AB355902, [AB355903] & [30] \\
\hline RN11 & Copenhagen, Denmark & 1 & AJ428514 & {$[47]$} \\
\hline RN06 & Vietnam & 1 & FJ842277 & This study \\
\hline RN13 & Tokyo, Japan & 1 & DQ673917 & {$[2]$} \\
\hline RN13 & (T2DN/Mcwi) & 1 & DQ673915 & [2] \\
\hline RN14 & (Sprague-Dawley) & 1 & AB033713 & {$[48]$} \\
\hline RN15 & (Wistar) & 1 & X14848 & {$[49]$} \\
\hline 11 & 7 countries & 16 & & \\
\hline
\end{tabular}

AN: Accession Number; LP: Limpopo Province; GP: Gauteng Province; KZN: KwaZulu-Natal Province; MP: Mpumalanga Province; WCP: Western Cape Province; CBD: Central Business District; IS: Informal Settlement; DM: Durban Natural Science Museum; []: Sequences that were not used for phylogenetic inference; * Unpublished record.

diversity reported for these species in previous studies [27-29,9,30,8,4].

Nucleotide and haplotype diversity indexes were determined in DNAsp version 5 [31]. Median-joining networks were constructed for each Rattus species in Network 4.5.1.0 [32] which takes pairwise haplotype differences into account to generate a network of parsimonious relationships that combines all possible trees using a one-step mutation model [33]. For $R$. rattus and $R$. tanezumi, haplotype networks were constructed from full-length as well as the partial cyt $b$ datasets. All $R$. norvegicus analyses were based on full-length gene sequences.

\section{Karyotyping}

Eight specimens typed as $R$. rattus and five as $R$. tanezumi following cyt $b$ sequencing were selected for karyotyping (Table 2). Metaphase chromosome spreads were prepared from either bone marrow samples flushed from the shafts of the tibiae and/or femorae of each sacrificed specimen as originally described by Hsu and Patton [34], or from skin fibroblast cultures established from $<1 \mathrm{~cm}^{2}$ ear biopsies, as described by Contrafatto et al. [35]. Giemsa-stained metaphase plates with the best morphology and least chromosomal overlaps were digitally recorded using a Vanox AHBS3 Olympus compound microscope connected to a coupled charged 
Table 2 Summary of the 149 genetically characterised Rattus specimens sampled from 29 localities in south Africa

\begin{tabular}{|c|c|c|c|c|c|}
\hline Localities & GPS & Metres a.s.I. & $\mathrm{N}$ & $\mathrm{N}$ (per species) & Haplotypes \\
\hline \multirow[t]{2}{*}{ Giyani (Nkomo-B), LP } & $23.416 \mathrm{~S}-30.786 \mathrm{E}$ & $448 \mathrm{~m}$ & 16 & R. tanezumi (7) & RT01* $^{*}$ \\
\hline & & & & R. rattus (9) & $\mathrm{RRO}^{*}$ \\
\hline Renosterkop, LP & $24.983 S-28.525 E$ & $1050 \mathrm{~m}$ & 1 & R. rattus (1) & RR04 \\
\hline \multirow[t]{2}{*}{ Tshilimbani, LP } & $22.767 S-30.200 E$ & $863 \mathrm{~m}$ & 23 & R. tanezumi (19) & RT01 \\
\hline & & & & R. rattus (4) & RR01 \\
\hline Sekhukhune (Bloublommetjieskloof), LP & $24.311 S-29.770 E$ & $743 \mathrm{~m}$ & 2 & R. rattus (2) & RR01 \\
\hline Johannesburg Zoological Gardens, GP & $26.166 \mathrm{~S}-28.037 \mathrm{E}$ & $1620 \mathrm{~m}$ & 8 & R. norvegicus (8) & RN01 \\
\hline \multirow[t]{2}{*}{ Moreleta Park, Pretoria, GP } & $25.828 \mathrm{~S}-28.288 \mathrm{E}$ & $1545 \mathrm{~m}$ & 2 & R. tanezumi (1) & RT01* \\
\hline & & & & R. rattus (1) & RR03 \\
\hline Roodeplaat, GP & $25.639 \mathrm{~S}-28.358 \mathrm{E}$ & $1225 \mathrm{~m}$ & 13 & R. tanezumi (13) & RR01 \\
\hline Rietondale, Pretoria, GP & $25.731 S-28.219 E$ & 1313 m & 1 & R. tanezumi (1) & RT01 \\
\hline Hillcrest, Pretoria, GP & $25.754 \mathrm{~S}-28.231 \mathrm{E}$ & $1380 \mathrm{~m}$ & 1 & R. rattus (1) & RRO4 \\
\hline \multirow[t]{4}{*}{ Hammanskraal, GP } & $25.371 \mathrm{~S}-28.188 \mathrm{E}$ & 1105 m & 18 & R. tanezumi (12) & RT01 \\
\hline & & & & R. rattus (4) & RRO3* \\
\hline & & & & R. rattus (1) & $\mathrm{RRO4}^{*}$ \\
\hline & & & & R. rattus (1) & RR05 \\
\hline \multirow[t]{6}{*}{ Tembisa, GP } & $26.002 S-28.213 E$ & 1605 m & 11 & R. tanezumi (3) & RT01 \\
\hline & & & & R. tanezumi (1) & RT02 \\
\hline & & & & R. rattus (1) & RR01 \\
\hline & & & & R. rattus (2) & RR03 \\
\hline & & & & R. norvegicus (1) & RN01 \\
\hline & & & & R. norvegicus (3) & RN12 \\
\hline \multirow[t]{2}{*}{ O.R. Tambo International Airport, GP } & $26.148 \mathrm{~S}-28.226 \mathrm{E}$ & 1693 m & 10 & R. norvegicus (1) & RN01 \\
\hline & & & & R. norvegicus (9) & RN12 \\
\hline Verena, MP & $25.504 \mathrm{~S}-29.027 \mathrm{E}$ & 1369 m & 1 & R. rattus (1) & RR03 \\
\hline Tholakele, KZN & $27.434 \mathrm{~S}-30.988 \mathrm{E}$ & $1100 \mathrm{~m}$ & 2 & R. tanezumi (2) & RT01 \\
\hline Mvuzini, KZN & $28.008 S-30.675 E$ & 1172 m & 3 & R. tanezumi (3) & RT01 \\
\hline Ophuzane, KZN & $27.486 \mathrm{~S}-30.934 \mathrm{E}$ & $827 \mathrm{~m}$ & 6 & R. tanezumi (6) & RT01 \\
\hline Richmond, KZN & $29.883 S-30.283 E$ & $860 \mathrm{~m}$ & 1 & R. tanezumi (1) & RT01* \\
\hline Melmoth, KZN & $28.567 S-31.317 E$ & $980 \mathrm{~m}$ & 1 & R. rattus (1) & RR10 \\
\hline Ladysmith, KZN & $28.550 \mathrm{~S}-29.783 \mathrm{E}$ & 1047 m & 1 & R. rattus (1) & RR11 \\
\hline Shongweni, Durban, KZN & $29.834 \mathrm{~S}-30.699 \mathrm{E}$ & $446 m$ & 2 & R. tanezumi (2) & RT01* \\
\hline Umkomaas, KZN & $30.217 S-30.800 E$ & $14 \mathrm{~m}$ & 5 & R. rattus (5) & $\mathrm{RRO4}^{*}$ \\
\hline Sydenham, Durban, KZN & $29.832 S-31.000 \mathrm{E}$ & $52 \mathrm{~m}$ & 2 & R. norvegicus (2) & RN01 \\
\hline Durban CBD, KZN & $29.859 \mathrm{~S}-31.016 \mathrm{E}$ & $22 \mathrm{~m}$ & 3 & R. norvegicus (3) & RN01 \\
\hline Montclair Park, Durban, KZN & $29.925 S-30.965 E$ & $33 \mathrm{~m}$ & 2 & R. norvegicus (2) & RN01 \\
\hline Cato Manor Rd, Durban, KZN & $29.858 \mathrm{~S}-30.978 \mathrm{E}$ & $88 \mathrm{~m}$ & 1 & R. norvegicus (1) & RN01 \\
\hline \multirow[t]{2}{*}{ Cato Crest IS, Durban, KZN } & $29.850 \mathrm{~S}-30.978 \mathrm{E}$ & $88 \mathrm{~m}$ & 4 & R. norvegicus (2) & RN01 \\
\hline & & & & R. norvegicus (2) & RN02 \\
\hline Durban Harbour, KZN & $29.871 \mathrm{~S}-31.048 \mathrm{E}$ & $6 \mathrm{~m}$ & 2 & R. norvegicus (2) & RN03 \\
\hline Warwick Ave, Durban, KZN & $29.858 \mathrm{~S}-31.010 \mathrm{E}$ & $22 \mathrm{~m}$ & 1 & R. norvegicus (1) & RN04 \\
\hline Manzini, Mcaphozini Area, Swaziland & $26.435 S-31.197 \mathrm{E}$ & $679 \mathrm{~m}$ & 6 & R. tanezumi (6) & RT01 \\
\hline
\end{tabular}

a.s.I.: above sea level; LP: Limpopo Province, South Africa; GP: Gauteng Province, South Africa; KZN: KwaZulu-Natal Province, South Africa; IA: International Airport; CBD: Central Business District; IS: Informal Settlement; * indicates haplotypes that were karyotyped.

device (CCD) video camera (COHU, Japan), linked in turn to an Intel-based personal computer equipped with a miroVideo PCTV capture board (Pinnacle Systems, Germany). Digitised metaphase spreads were used to construct at least two karyograms per specimen using the open-source package Gimp, version 1.2.3 http://www.gimp.org. The diploid number was determined by establishing the modal number of chromosomes from chromosome counts of no less than 20 metaphase spreads per individual, following the guidelines of Yosida [36] for Rattus karyogram construction using uniformly stained chromosomes. 


\section{Ecological niche modeling}

Notwithstanding acknowledged limitations, bioclimatic data from the native range ("niche") of an invasive species can be used to predict the extent of invasion in a target area [37-40]. This approach assumes climatic matching of native and target areas. To test this assumption, using principal components analysis (PCA), we compared the bioclimatic space occupied by 13 geo-referenced $R$. tanezumi distribution records from the invasive range of the species in South Africa and Swaziland (precision of 0.001 degrees) with that obtained from 134 unique-locality occurrence records from the combined naturalised and native range extracted from public domain databases provided by the Global Biodiversity Information Facility http:// www.gbif.org. Altitude and eight bioclimatic variables (WORLDCLIM version 1.4: http://www.worldclim.org/ bioclim; [41]) were originally chosen (see additional file 1, Table S1), reflecting means, extremes, and seasonal variation of temperature and precipitation, viz. Bio1 (mean annual temperature), Bio4 (temperature seasonality), Bio5 (maximum temperature of warmest month), Bio6 (minimum temperature of coldest month), Bio12 (annual precipitation), Bio13 (precipitation of wettest month), Bio14 (precipitation of driest month), and Bio15 (precipitation seasonality). In order to compare the relative importance of human and climate variables in the respective ecological niches of the species from its invasive and naturalised ranges, "human footprint", a global map of human influence on the landscape was also used [42].

Next we estimated the ecological niche for $R$. tanezumi based on 119 native and naturalised occurrence records, in order to predict the species' potential invasive distribution in sub-Saharan Africa, and to compare this with the actual known invasive range. We used the MaxEnt (Maximum Entropy; [43]) programme which employs a general machine learning algorithm, because it has been shown to perform well with presence-only data and with small sample sizes, and generally outperforms alternative "climatic envelope" models such as GARP and BIOCLIM [44]. To correct for potential statistical over-fitting due to high correlation coefficients between certain bioclimatic variables, we summarised the pattern of correlations between the original set of eight bioclimatic variables by means of an Unweighted Pair-Group Method with Averages (UPGMA) correlation phenogram. Individual variables were selected from four distinct (independent) clusters (data not shown): Bio1 (mean annual temperature), Bio4 (temperature seasonality), Bio12 (annual precipitation), Bio14 (precipitation of driest month). Given the known commensalism of rats, including $R$. tanezumi, and following Ficetola et al. [38] "human footprint" was included as a fifth variable.
The environmental data were set to a spatial grid resolution of 2.5 arc minutes and were clipped to an area accommodating the native and naturalised ranges of $R$. tanezumi. The projection layer (target area) was clipped to sub-Saharan African south of 13 degrees north. The MaxEnt model was run with $70 \%$ presence records used for training and 30\% for random testing, with the regularization multiplier set to 1.0, maximum number of iterations to 1500 , convergence threshold to $1 \times 10-5$ and output format to logistic. Duplicate records (in the same pixel) were excluded. Model performance was assessed with proportion of presences correctly classified (sensitivity), proportion of absences correctly classified (specificity), and discrimination ability (area under the curve [AUC] of a receiver operating characteristic [ROC] plot of sensitivity versus 1-specificity). Since MaxEnt produces a continuous probability (ranging from 0 to 1.0), the continuous model output was transformed to a map representing probabilities of occurrence. The contribution of each explanatory variable to model performance was evaluated with a jackknife procedure implemented in MaxEnt, where variables are successively omitted and then used in isolation to measure their relative, as well as their absolute contribution to the model.

\section{Results}

\section{Genetic analyses}

The 44-taxon Rattus ingroup dataset contained 183 variable and 165 parsimony-informative sites across the 1140 nucleotide (nt) cyt $b$ gene region. As would be expected for a coding gene, the proportion of base position mutations was $3^{\text {rd }}>1^{\text {st }}>2^{\text {nd }}$, with $138(75 \%)$ of the mutations occurring in the $3^{\text {rd }}$ base position, 39 $(21 \%)$ in the $1^{\text {st }}$ base position and the remaining $6(4 \%)$ being attributed to $2^{\text {nd }}$ base position mutations.

For the 47-taxon dataset, inclusive of three Mus outgroup sequences, the $\mathrm{GTR}+\mathrm{I}+\mathrm{G}$ model $(\mathrm{I}=0.5084$ and $\mathrm{G}=0.8058$ ) with nucleotide frequencies of $\mathrm{A}=0.308, \mathrm{C}$ $=0.288, \mathrm{G}=0.123, \mathrm{~T}=0.281$, was selected as the bestfit model under the AIC in ModelTest. The cyt $b$ gene tree (Figure 1) recovered three monophyletic Rattus lineages in south Africa. Nodes that had $\geq 70 \%$ bootstrap support in the phenetic analyses generally had high levels of support in the maximum likelihood analyses (Figure 1). The two South African $R$. tanezumi haplotypes, RT01 and RT02, formed a monophyletic lineage (100\% support; Figure 1) and differed from each other at just one nucleotide site at position 538 in the full-length dataset (see additional file 2, Figure S2a) and position 501 in the partial cyt $b$ dataset (Figure 2). This first base mutation results in a non-synonymous alanine to threonine amino acid substitution. For $R$. rattus, three discrete lineages were recovered for the South 
African specimens (Figure 1). Haplotype RR01, which occurred in 16 individuals sampled at four South Africa sites, was also present in an individual from Tanzania (Tables 1 \& 2). The RR01 haplotype, was sister to haplotype RR02 from Indonesia (73-88\% nodal support, Figure 1) differing from it by four mutational steps (see additional file 2, Figure S2b). Haplotypes RR04 and RR05 clustered within a lineage containing representatives from New Zealand (RR06) and Japan (RR07), with high levels of support (87-100\% nodal support, Figure 1 ). The third South African haplotype lineage, RR03, is separated from the former South Africa-New ZealandJapan cluster by at least six mutational steps (Figure 3), and unrelated to all other haplotypes included in the full-length (Figure 1) and partial dataset (see additional file 3, Figure S3) analyses. For $R$. norvegicus, two discrete South African lineages were recovered. Three of the five South African haplotypes (RN02, RN03 and RN04) were linked to haplotype RN01, recovered from 20 South African specimens (Figure 4), which was also represented by laboratory strain, BN/SsNHsdMCW (Genbank accession number AY172581; Figure 1). Haplotype RN12 which represents the second $R$. norvegicus lineage in South Africa, predominated at two Gauteng Province sites, and was sister to RN13, a haplotype present in the T2DN/Mcwi lab strain and in a wild-caught individual from Japan (Figure 1), differing from the latter two sequences at a single nucleotide site (Figure 4).

Haplotype diversity (h) and nucleotide diversity $(\pi)$ values determined from complete gene sequence datasets for each of the three south African Rattus species were: (i) $R$. norvegicus: $\mathrm{h}=0.613$ (5 haplotypes from 37 sequences), $\pi=0.00379$, (ii) $R$. tanezumi: $\mathrm{h}=0.026(2$ haplotypes from 77 sequences), $\pi=0.00002$, and (iii) $R$. rattus: $\mathrm{h}=0.667$ (4 haplotypes from 33 sequences), $\pi$ $=0.00514$. Between-species mean p-distance calculated in Mega4 [23] was 3.9\% for the two sibling species of the $R$. rattus species complex, $R$. tanezumi- $R$. rattus, $11.9 \%$ for $R$. tanezumi-R. norvegicus and $11.2 \%$ for $R$. rattus- $R$. norvegicus.

Karyotyping of eight $R$. rattus individuals recovered diploid chromosome numbers of 38 in six specimens and 40 in two specimens (Figure 5). All five $R$. tanezumi specimens had the $2 n=42$ karyotype that is characteristic of this species (Figure 5). Two of the $R$. rattus individuals (SA255 and SA258) which were identical across the cyt $b$ gene (both haplotype RR04) and which were sampled from the same locality (Umkomaas, KwaZulu-Natal Province), were found to have different chromosome numbers (Figure 5 ). The $R$. rattus $2 n=38$ arrangement was characterized by nine pairs of acrocentric chromosomes, metacentric $M_{1}$ and $M_{2}$ (marker) chromosomes, seven additional pairs of metacentric chromosomes and one pair of acrocentric X chromosomes, conforming precisely to the "Oceania" $R$. rattus arrangement described by Yosida et al. [45]. Marker chromosomes $M_{1}$ and $M_{2}$ represent centric fusion events involving chromosomes $4 / 7$ and 11/12 respectively of the putative ancestral karyotype [45]. The $2 n=40$ arrangement was identical to that of the $2 n=38$, except that it contained an additional pair (pair 21) derived from a centric fission event. In this respect, this arrangement represents an intermediate stage between the Oceania form and the "Mauritian" form [45] which was derived from the $2 n=38$ form by two centric fission events, and which has not been documented to date. The $2 n=42$ arrangement matched R. tanezumi [45] and was characterized by 13 acrocentric chromosome pairs, seven pairs of metacentric chromosomes and acrocentric X and Y chromosomes. No marker chromosomes were identified for this arrangement (Figure 5).

\section{Geographical distribution}

Rattus tanezumi occurred in three provinces at sampling sites ranging from $446 \mathrm{~m}$ above sea level (a.s.l.) to 1605 $\mathrm{m}$ a.s.l. (Table 2; Figure 6a). R. rattus was recorded from all four South African Provinces sampled in this study, at altitudes ranging from $14 \mathrm{~m}$ to $1605 \mathrm{~m}$ a.s.l and from Cape Town (altitude not known) in a previous study [4]. Although $R$. norvegicus was only recorded in the Gauteng and KwaZulu-Natal Provinces, it had the broadest altitudinal range occurring at sites ranging from $6 \mathrm{~m}$ to 1693 $\mathrm{m}$ a.s.l. Rattus tanezumi and $R$. rattus occurred sympatrically at two Limpopo Province sites (Giyani and Tshilimbani) and at three sites in Gauteng Province (Figure 6a), viz. Moreleta Park (a suburb of Pretoria) and in Tembisa and Hammanskraal which are both townships incorporated within the greater metropolitan areas of Johannesburg and Pretoria, respectively. The three invasive Rattus species occurred sympatrically at a single site, Tembisa, which like Hammanskraal is a peri-urban township of Gauteng Province that incorporates areas of informal human settlement. Intra-specific diversity was also highest in townships within the major metropolitan areas of Durban, Pretoria and Johannesburg. Two $R$. norvegicus haplotypes (RN01 and RN02) were recovered from four Cato Crest specimens, three $R$. rattus haplotypes (RR03, RR04 and RR05) were identified from six Hammanskraal individuals and for Tembisa two haplotypes (RT01 and RT02) were identified from the four R. tanezumi individuals, two haplotypes (RR01 and RR03) from three $R$. rattus individuals and two haplotypes (RN01 and RN12) from four $R$. norvegicus individuals. This corresponds to a total of six Rattus haplotypes from just 11 specimens in Tembisa and to four Rattus haplotypes from the 18 individuals in Hammanskraal.

Analyses based on partial cyt $b$ sequences and inclusive of $R$. rattus from diverse western Indian Ocean 


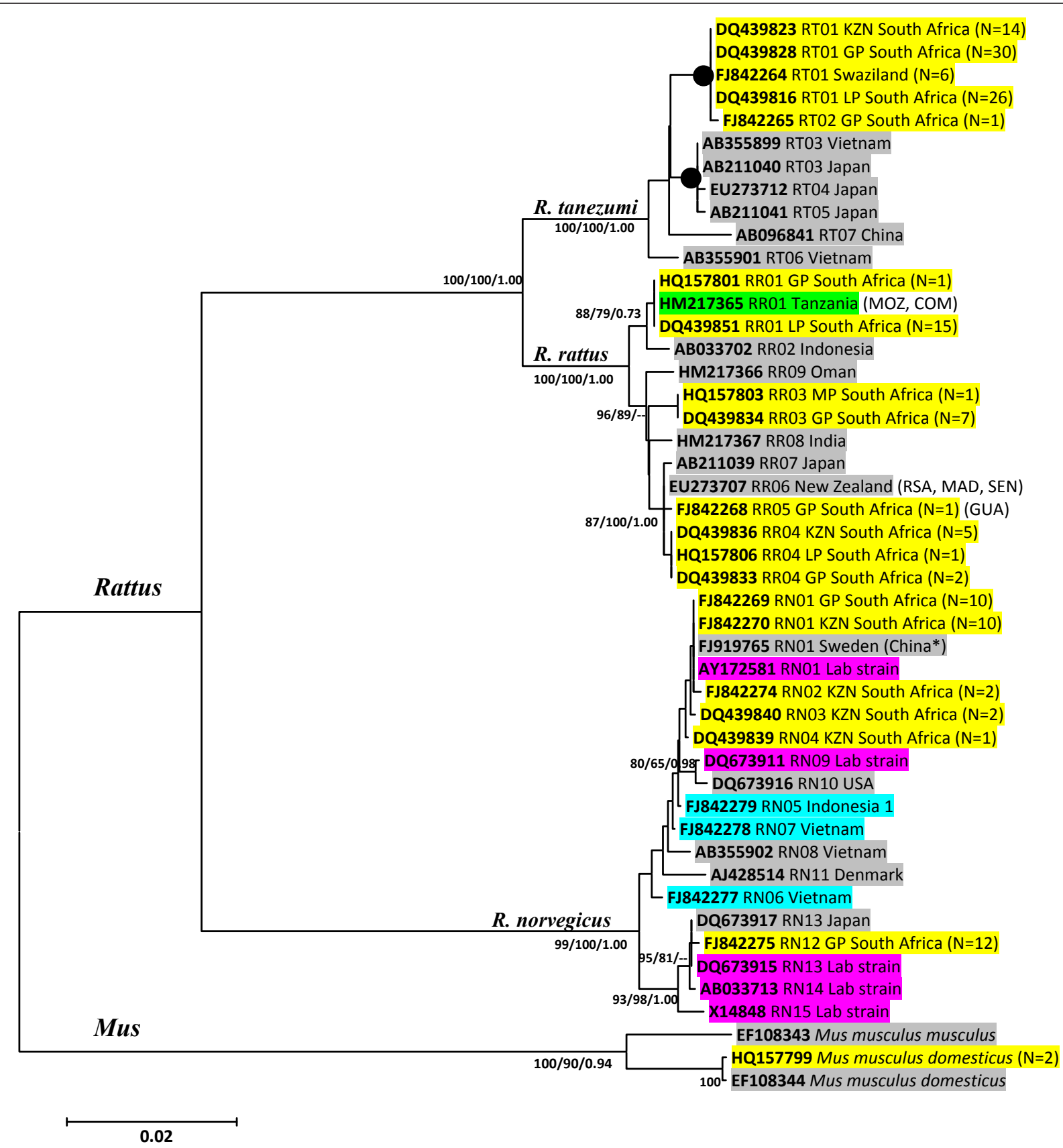

Figure 1 Cytochrome $b$ gene tree inferred using full-length sequence data $(1140 \mathrm{bp})$ and depicting the genetic relatedness of the three Rattus species haplotypes in South Africa. Taxon names comprise the Genbank accession number, followed by the country of origin (for South African samples this is preceded by a province code: $L P=$ Limpopo Province, MP = Mpumalanga Province, GP = Gauteng Province, KZN = KwaZulu-Natal), haplotype and the number of individuals characterised. Nodal support values are given in percentages and are indicated ME/ML/BPP next to the relevant nodes. - indicates nodes that were either not recovered or that had support values $<50$ for ME and $<70$ for ML and BPP. Haplotypes are colour-coded as follows to indicate the region and source of the data: Yellow = Southern Africa (This study), Blue $=$ Outside Africa (This study), Green = Africa (Genbank), Grey = Outside Africa (Genbank), Purple = Laboratory strain (Genbank). Terminal nodes connecting different haplotypes and having $\geq 99$ percent support from all three methods of inference are denoted by a black-filled circle. Country codes given in brackets behind a taxon name, indicate shared presence of a particular haplotype identified from the partial $1043 \mathrm{bp}$ dataset (additional file 3, Figure S3) and are abbreviated: $\mathrm{COM}=$ Comores, $\mathrm{MOZ}=$ Mozambique, GUA = Guadeloupe, MAD = Madagascar, RSA = Republic of South Africa and SEN = Senegal. 


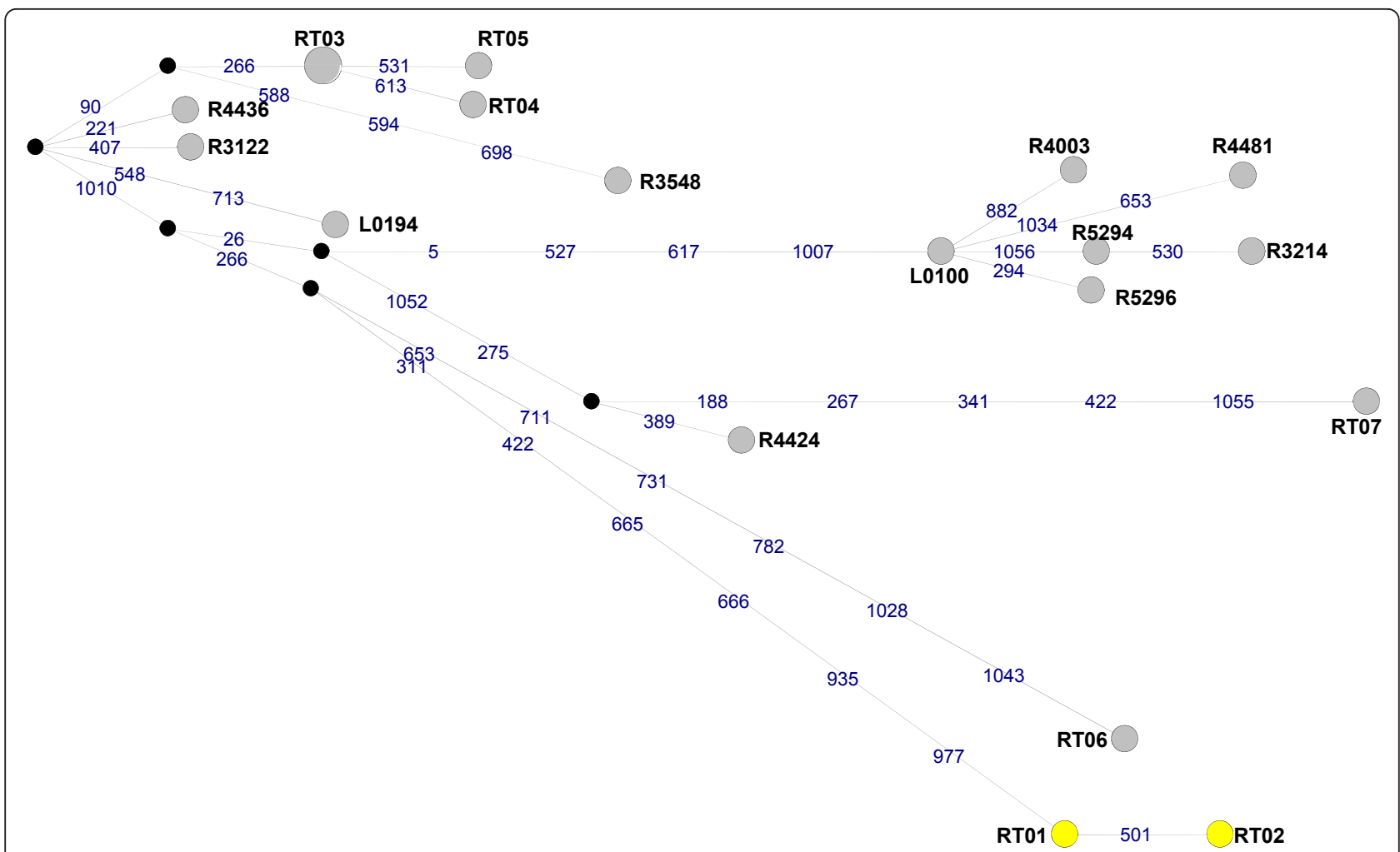

Figure 2 Median-joining network of Rattus tanezumi cytochrome $b$ (cyt $b$ ) haplotypes based on partial (1077 bp) gene sequences. Haplotype colour coding is consistent with that used in Figure 1, viz. Yellow = south Africa (This study), Grey = Outside Africa (Genbank). Each of the mutational steps separating haplotypes is indicated in blue and corresponds to the relevant position in the cyt $b$ gene, whilst black nodes correspond to median vectors. Haplotype numbers are the same as those provided in Table 1. Additional haplotype numbers correspond to the laboratory numbers assigned in the Pagès et al. [8] study.

islands, Africa and from Guadeloupe (Lesser Antilles, Caribbean Sea) revealed that the RR01 haplotype also occurs on Grande Comore, Tanzania and Mozambique and that this haplotype is sister to a clade containing haplotypes from India, Yemen and Indonesia (see additional file 3, Figure S3). South African haplotype RR03 was unrelated to any of the presently-available $R$. rattus cyt $b$ sequences, whilst the lineage containing South African RR04 and RR05 haplotypes also included two specimens from Cape Town in South Africa [4] and specimens from New Zealand, Japan, Oman, Guadeloupe, Senegal, Reunion Island and Madagascar (see additional file 3, Figure S3). The additionally-available partial $R$. tanezumi data for specimens from Laos and Indonesia revealed the existence of multiple $R$. tanezumi lineages and identified 16 haplotypes (Figure 2); the South African haplotypes RT-01 and RT-02 were, however, unrelated to any of these, being separated by at least nine mutational steps from any other haplotype.

Our sample of public records of occurrence was strongly biased towards the presumed naturalised range of the species in the Philippines and Indonesia and included just four localities in China and Tibet occurring within the probable native range of this species which is likely to be restricted to Myanmar, northern Indochina (northern Laos, central to northern Vietnam, northern Thailand) through to southern China (K. Aplin, pers. comm.). With the exception of the four northern localities in Tibet and China (including Hong Kong and Hainan Island), specimens occurring in the naturalised range of $R$. tanezumi encompass a climatic space that is somewhat distinct from that occupied by $R$. tanezumi in South Africa and Swaziland (Figure 6 \& Figure 7). As very few public records were available for the assumed native distribution, we expected the model to show a measure of under-prediction of both native+naturalised and target (predicted invasive) niches. Based on examination of eigenvector loadings of variables from the PCA (not shown), the separation of the South Africa, Chinese and Tibetan records on the second principal component (PC2) is influenced strongly by a contrast between temperature variables (high positive loading for mean average temperature and minimum monthly temperature) and two variables relating to seasonality of temperature and precipitation (which showed high negative loadings on PC2; Figure 7). Thus, the above-mentioned localities 


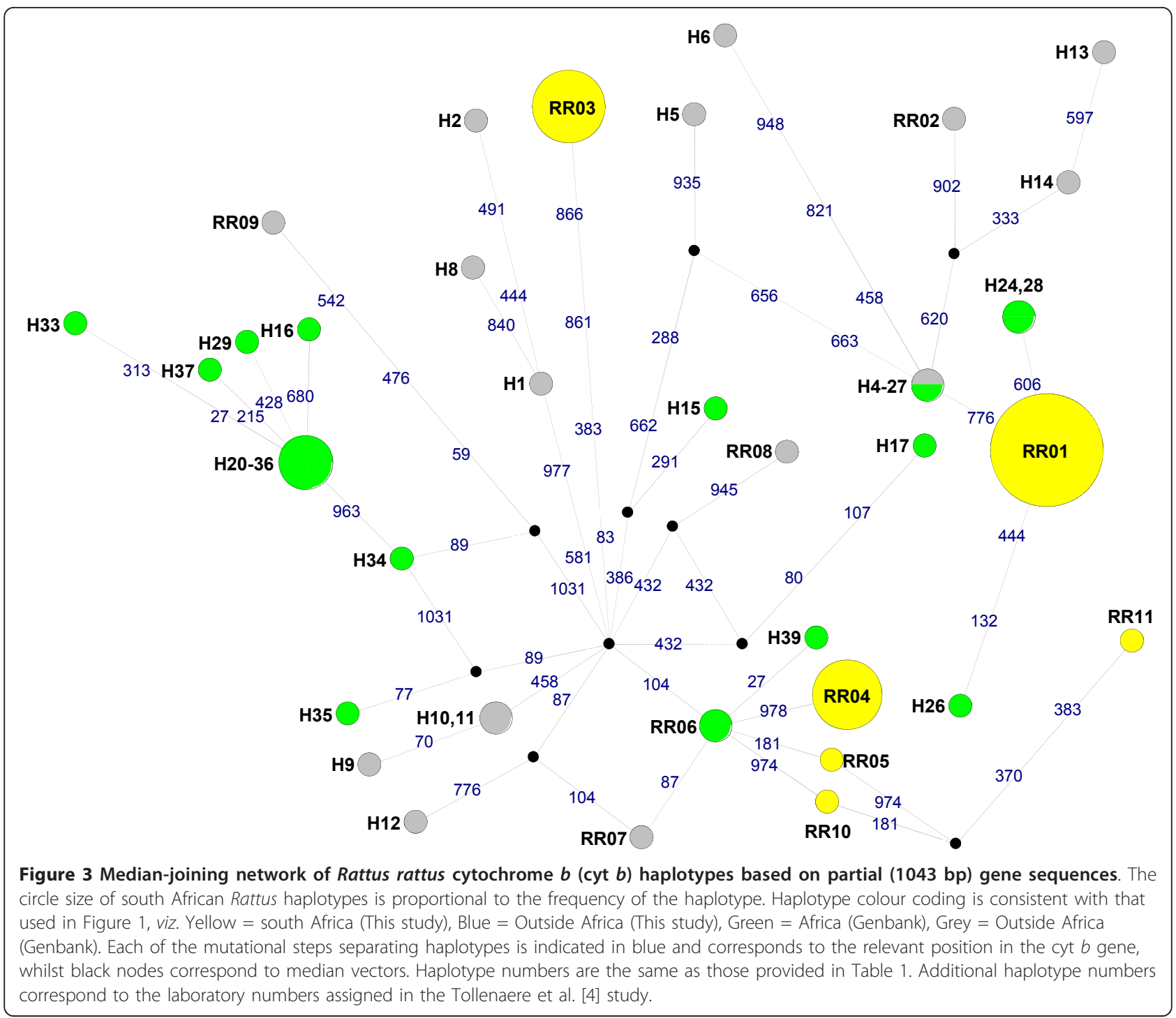

(corresponding to the invasive range of South Africa and the presumed original native range in Asia) are distinguished by low mean and minimum temperatures and pronounced seasonality compared to records from the naturalised range of the species in the Philippines and Indonesia.

MaxEnt analyses using combined naturalised and native distribution points and five environmental variables (four bioclimatic variables and human footprint) predicted the potential invasive occurrence of $R$. tanezumi in Africa to be mostly limited to the equatorial belt and the Ethiopian Rift (Figure 8). As indicated above, this model most likely reflected a degree of under-prediction of the potential invasive distribution in Africa. The MaxEnt algorithm converged after 840 iterations with a regularized training gain of 2.03. Model performance as assessed by AUC was 0.969 for the training AUC and
0.927 for the test AUC, indicating efficient classification of suitable versus unsuitable habitats. Bio4 (temperature seasonality) explained most of the variation (52.2\%), and it was also the variable with the highest individual gain (having the most useful information in itself). However, human footprint was the environmental variable that decreased the overall gain of the model most when omitted indicating that it contains information that is not present in the other variables. High habitat suitability of $R$. tanezumi was associated with low values of temperature seasonality and high values of annual precipitation and human influence.

\section{Discussion and Conclusions}

The presence of $R$. tanezumi in South Africa was confirmed using a molecular and cytogenetic characterisation approach and increases the number of invasive, 


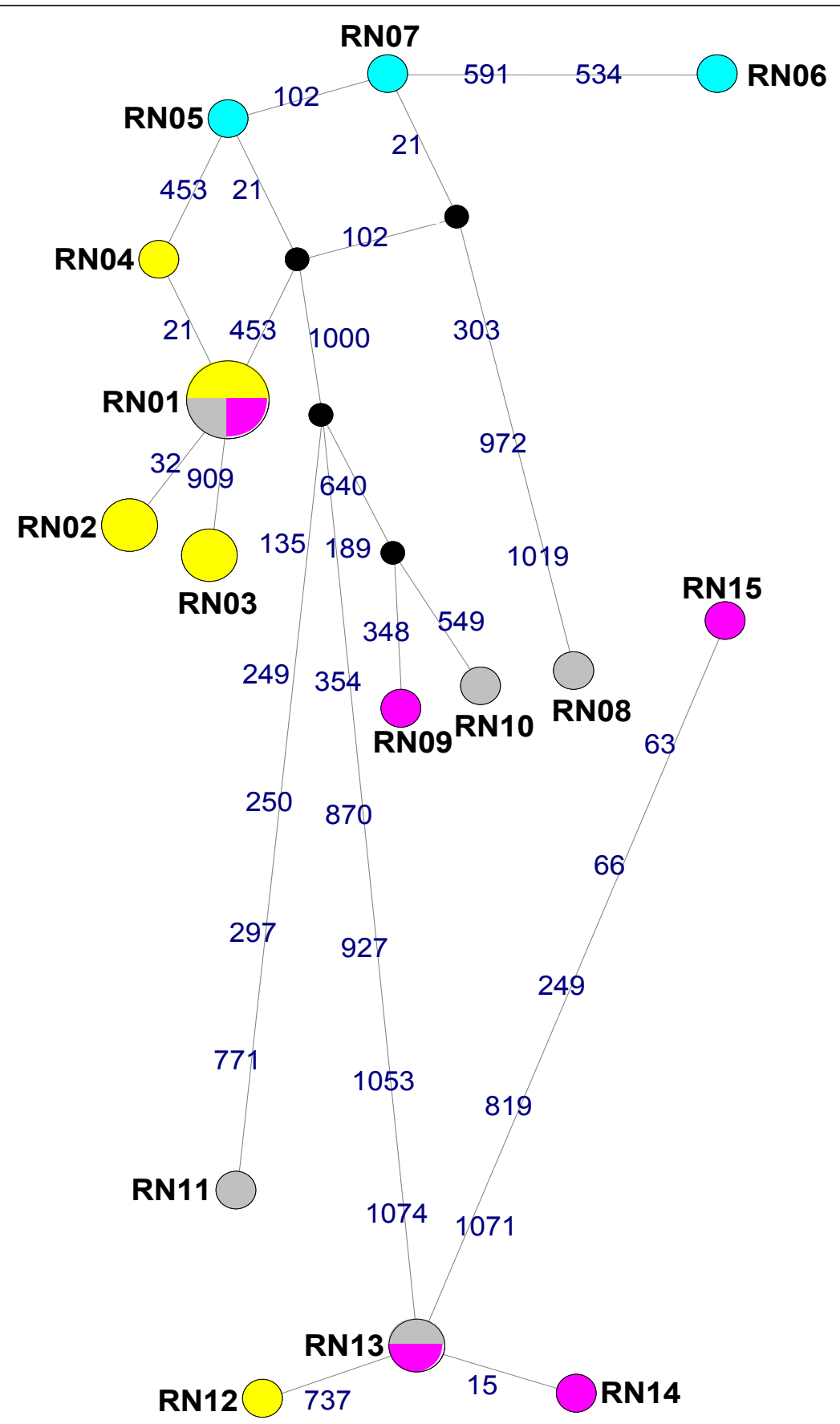

Figure 4 Median-joining network of Rattus norvegicus cytochrome $b$ (cyt $b$ ) haplotypes based on full-length gene sequences. The circle size of south African Rattus haplotypes is proportional to the frequency of the haplotype. Haplotype colour coding is consistent with that used in Figure 1, viz. Yellow = south Africa (This study), Blue = Outside Africa (This study), Grey = Outside Africa (Genbank), Purple = Laboratory strains (Genbank). Each of the mutational steps separating haplotypes is indicated in blue and corresponds to the relevant position in the cyt $b$ gene, whilst black nodes correspond to median vectors. Haplotype numbers are the same as those provided in Table 1.

commensal Rattus species, from two to three. Haplotype diversity was low for all three invasive Rattus species in South Africa with just two haplotypes identified for R. tanezumi (RT01 and RT02), seven for $R$. rattus (RR01, RR03, RR04, RR05, RR06, RR10 and RR11) and five for $R$. norvegicus (RN01, RN02, RN03, RN04 and $\mathrm{RN} 12)$. The cyt $b$ gene phylogeny recovered three discrete monophyletic lineages for $R$. rattus, two for $R$. norvegicus and one for $R$. tanezumi, with each lineage being indicative of a separate introduction. Thus, unlike 


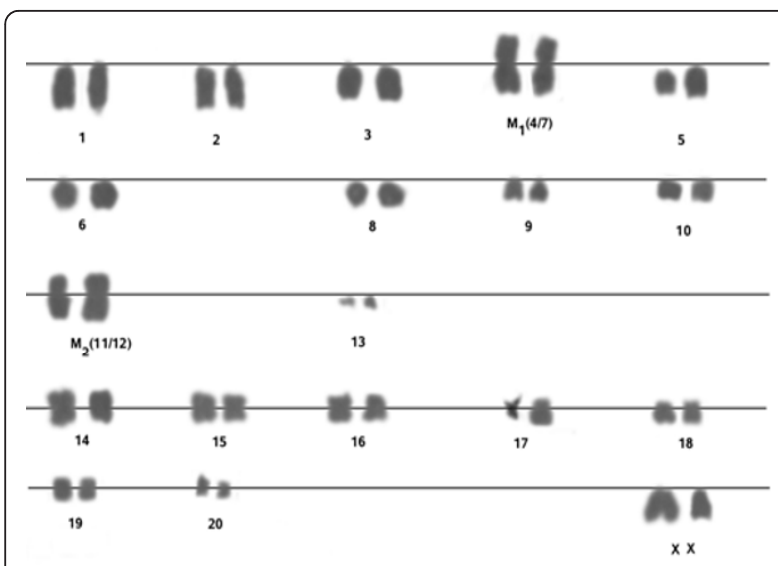

SA258 $2 n=38$

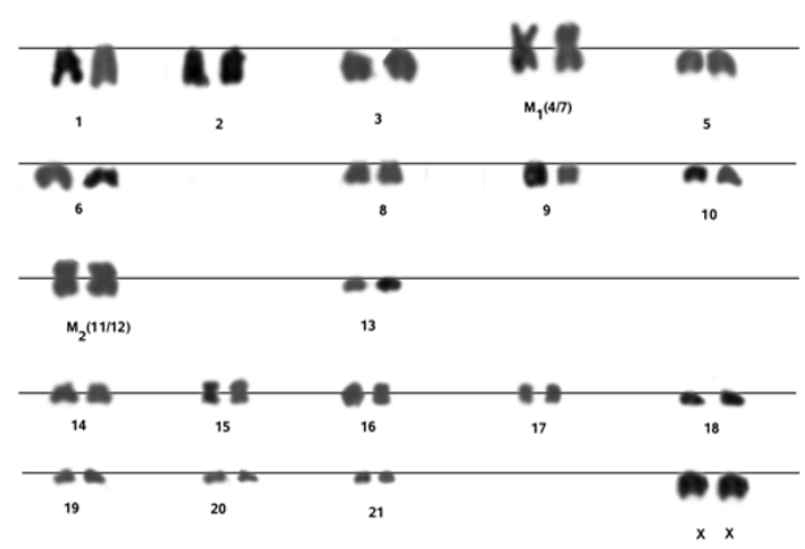

SA255 $2 n=40$

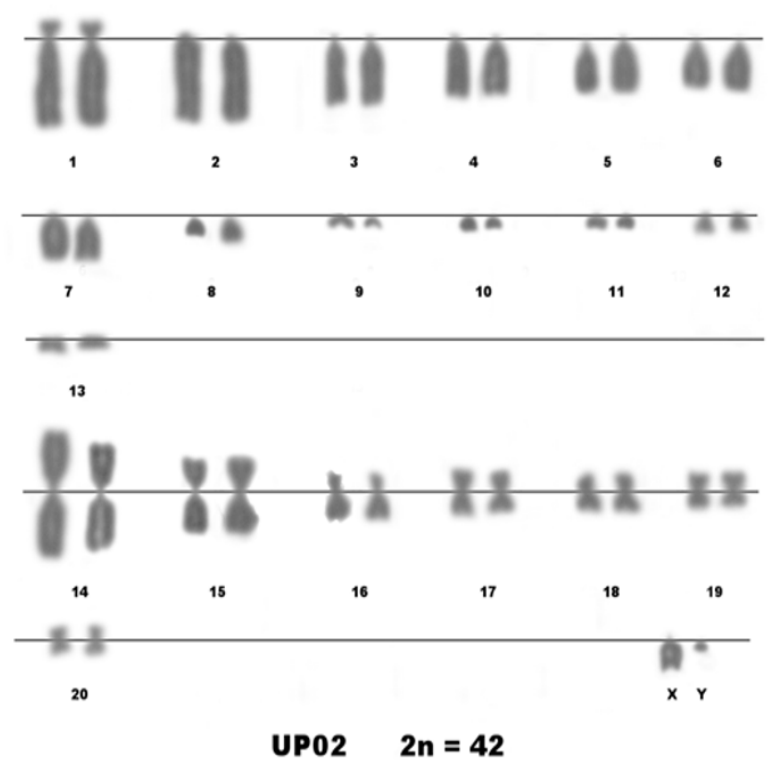

Figure 5 Rattus species karyotypes from South Africa. Rattus rattus (haplotype RR04, $2 n=38$ ) and Rattus rattus (haplotype RR04, $2 n=40$ ) above, with Rattus tanezumi (haplotype RT01, $2 n=42$ ) depicted below.

invasive $R$. rattus in Madagascar which rapidly diversified and expanded its range following what appeared to be a single introduction [33,4], cyt $b$ sequence analyses of Rattus species from South Africa indicate that, with the exception of $R$. tanezumi, at least three $R$. rattus and two $R$. norvegicus introductions have occurred (Figure 1 and additional file 3, Figure S3). A star-like radiation of haplotypes, such as that observed for Madagascar $[33,4]$ was only noted for one $R$. norvegicus lineage and for one $R$. rattus lineage, indicating that these two lineages most likely represent the earliest introductions to South Africa.

Comparison of South African Rattus sequence data with available homologous data for conspecifics revealed that two of the six Rattus lineage introduced to South Africa are unrelated and distinct from all other available haplotypes. In particular, the origin of the cryptic Rattus species, $R$. tanezumi remains obscure despite the availability of data from a number of localities within its native and naturalised ranges (Figure 2) as does the origin of the $R$. rattus haplotype RR03. The remaining two $R$. rattus haplotypes recovered from South Africa were quite widespread in Africa and its Indian oceanic islands [4]. Haplotypes RR04 and RR10 from South Africa, RR05 from South Africa and Guadeloupe, H39 from Reunion Island and RR07 from Japan, linked by one mutational step each to the RR06 haplotype which also occurs in New Zealand, Senegal, Madagascar and to two 


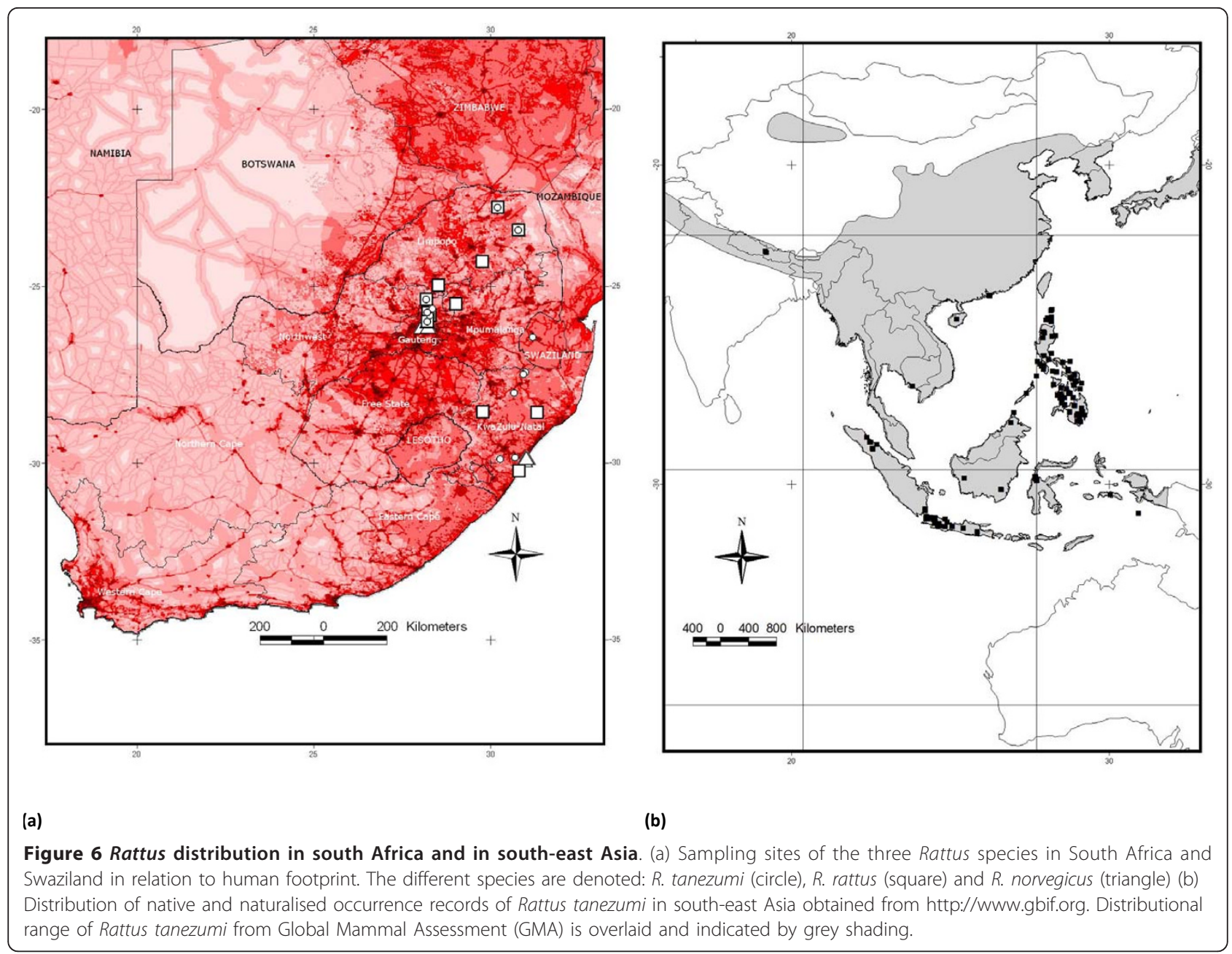

specimens from Cape Town, South Africa (Figure 3). Similarly, the RR01 haplotype identified in South Africa and which also occurs in Tanzania, Mozambique and Isle Grande Comore, linked to RR02 from Indonesia by four mutational steps (see additional file 2, Figure S2) with high levels of support (Figure 1). Common ancestry between wild-caught South African $R$. norvegicus haplotype RN12 and haplotype RN13 was indicated by the single mutational step separating these haplotypes (Figure 4) and high levels of bootstrap support (Figure 1). Of interest is that both $R$. norvegicus lineages in South Africa revealed links with laboratory strains, viz. RN01 is represented by $\mathrm{BN} / \mathrm{SsNH} \mathrm{HdMCW}$, whilst the T2DN/ Mcwi strain which corresponds to haplotype RN13 and is sister to RN12, was also identified in a wild-caught rat from Japan.

All three Rattus species were sampled in the Gauteng and KwaZulu-Natal Provinces of north-central and central-eastern South Africa, respectively, but $R$. norvegicus has to date, not been found in Limpopo Province in northern South Africa (Table 2; Figure 6a). Although the distributional range of $R$. norvegicus does not appear to extend as far north as the other Rattus species (Figure 6a), its presence at inland sites in Gauteng Province is significant as previous records indicated that this species was restricted to coastal areas of South Africa [22]. As $R$. norvegicus is morphologically, readily distinguished from $R$. rattus, and $R$. tanezumi, on its distinctly large overall body size alone, it is likely that its presence in the interior of the country represents a recent incursion and explains why co-occurrence of all three species has only been found at one South African site thus far. As viable hybridisation has been shown to occur between $R$. rattus and $R$. tanezumi [29] it is likely that some degree of introgression is occurring at the five sites at which these species were found to co-occur in South Africa, and should be investigated further using nuclear and mitochondrial gene characterisation in combination with karyotyping.

MaxEnt ecological niche modelling based on the combined naturalised and native range of $R$. tanezumi failed to predict the known (and presumably recent) invasive range of the species in the interior of South Africa. Although this 


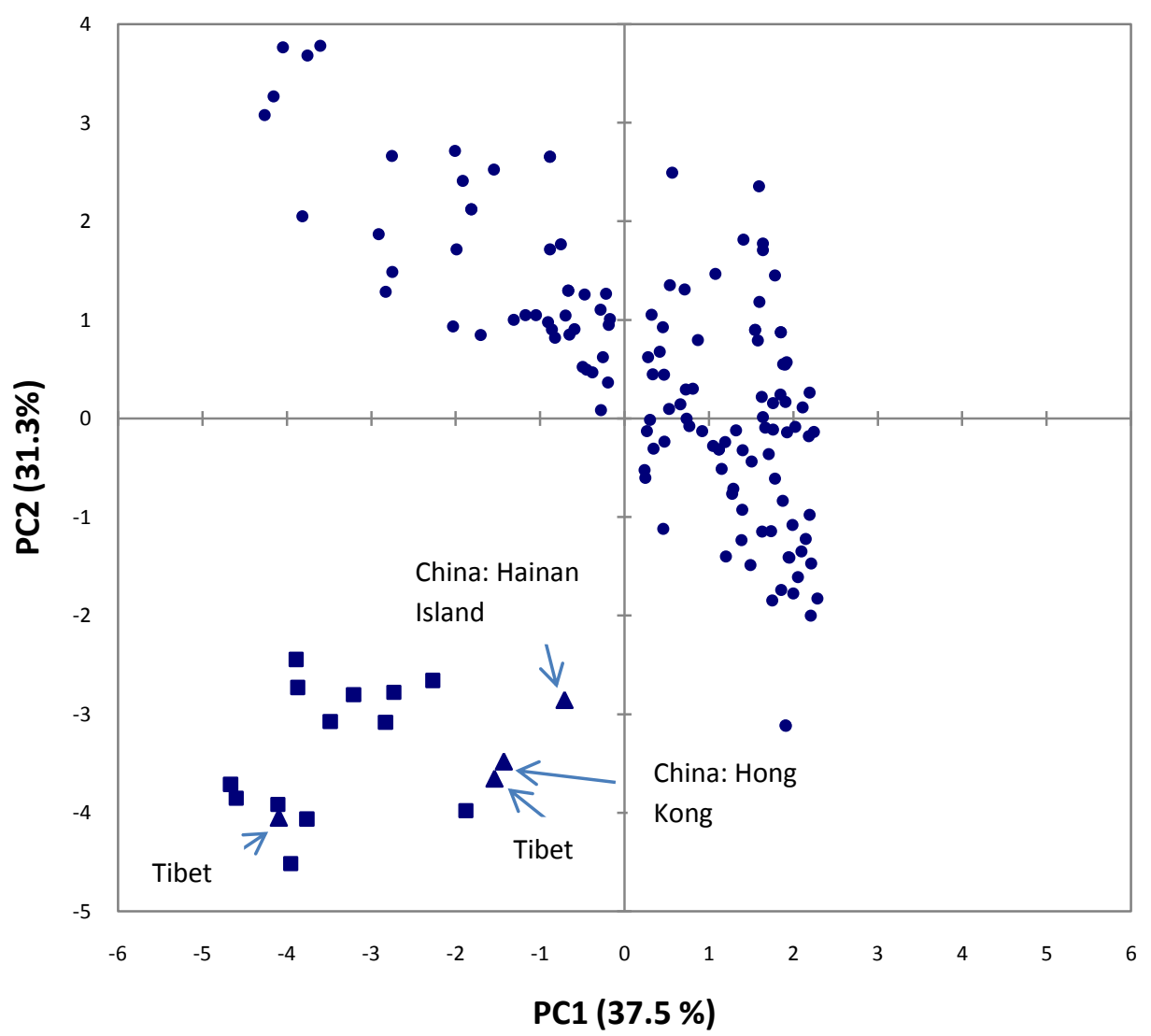

Figure 7 Principal component analysis (PCA) of eight bioclimatic variables, altitude and 'human footprint' in a sample of naturalised (circles), native (triangles) and invasive South African (squares) records of Rattus tanezumi occurrence.

could be partly explained by under-prediction due to the incomplete sampling of the presumed original native range (only four records available) compared to the naturalised range, it is also conceivable that factors other than climate have facilitated the spread of the species in South Africa. If it could be shown that South African populations originated from the more temperate, presumed-native range of the species in Asia, niche similarity could explain its presence in South Africa (as demonstrated by the proximity of the records in the bioclimatic space in Figure 7). Nevertheless, even within south-eastern Asia the species has spread from its original native range in more temperate climates, to invade tropical and equatorial areas extending into the Philippines and Indonesia, suggesting the importance of factors other than climate. Given the highly commensal nature of $R$. tanezumi, it is noteworthy that records of this species in South Africa largely coincided with nodes of high human influence (human footprint; Figure 6a). Given the extent of historical shipping trade between South Africa and the Far East, the accidental introduction of $R$. tanezumi is easily explained, where after this species has apparently exploited the commensal niche, using major transport routes to disperse as far inland as the commercial-industrial hub of Gauteng Province. The further dispersal of this species to the northern Limpopo Province could be explained by the presence of the N1 highway and dense rural populations and markets in the Venda region, (where $R$. tanezumi was first recorded in South Africa).

The origins of the Rattus species introduced into South Africa could not be accurately pin-pointed and will remain obscure until a comprehensive database that includes all invasive Rattus species from throughout their native and introduced geographical ranges, becomes available. In this regard, this study has made a valuable contribution to documenting feral $R$. norvegicus diversity and distribution, as only a limited number of complete cyt $b$ haplotype sequences were available prior to this study (Table 1 ). The additional data generated for the five South African $R$. norvegicus haplotypes and for three wild-caught animals from Vietnam and Indonesia, contribute to wild-caught $R$. norvegicus haplotype diversity data and would benefit from similar studies in all regions in which this invasive species occurs. The number of full-length reference cyt $b$ gene sequences for $R$. rattus has also increased. Despite a larger number of reference haplotype sequences being available from the naturalised and native ranges of $R$. tanezumi [8] 


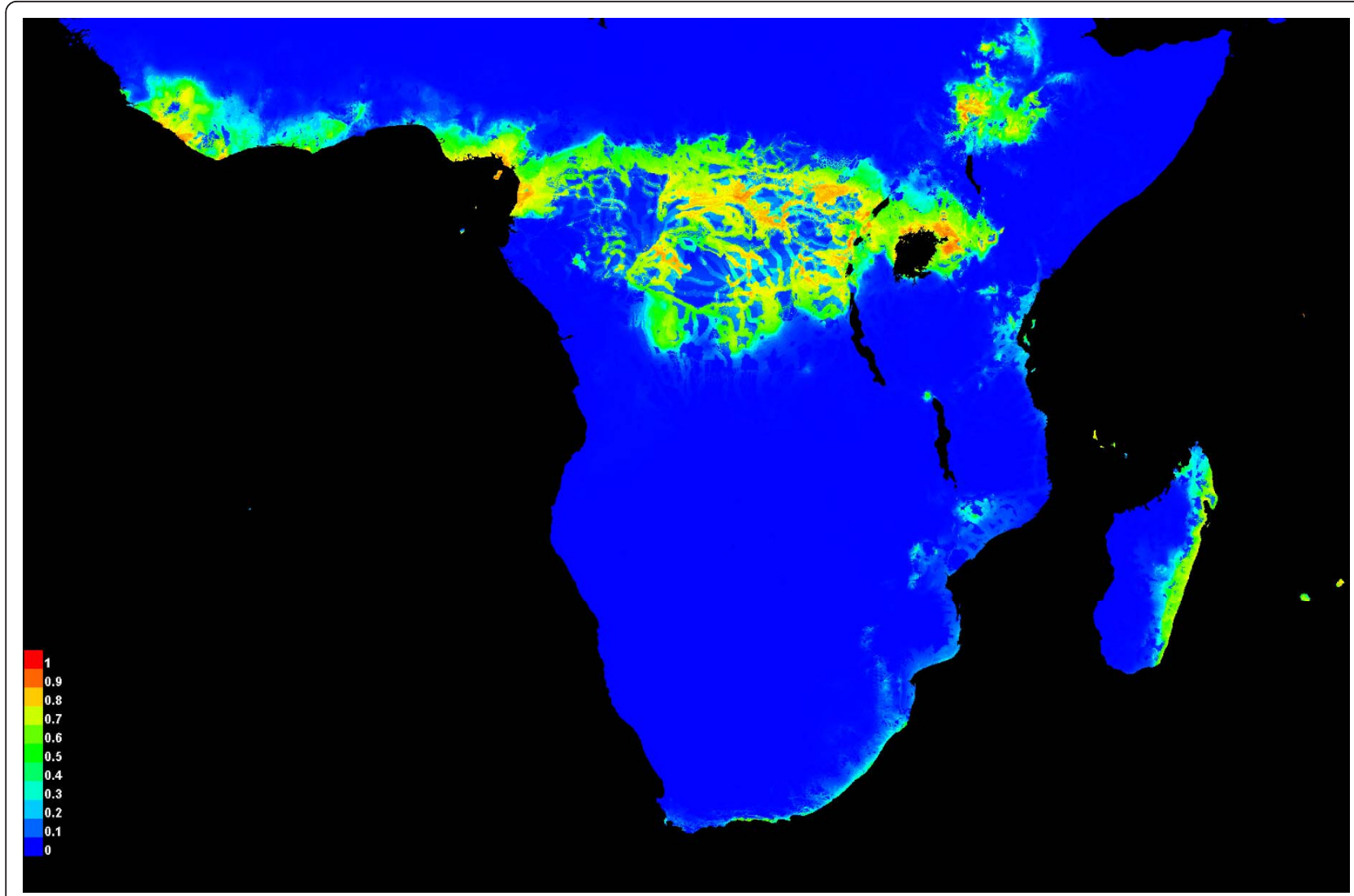

Figure 8 MaxEnt model showing predicted geographical distribution of the invasive range of Rattus tanezumi in sub-Saharan Africa, based on the naturalised range.

and $R$. rattus [4], these were insufficient to provide insight into the likely origin of the $R$. tanezumi lineage introduced into South Africa, which differed by a minimum of nine mutational steps from all available sequences, or for the R. rattus RR03 lineage. Sampling and sequencing efforts need to be intensified globally for these three invasive $R a t$ tus species in order to map migration pathways more accurately and to assess factors influencing and limiting their co-occurrence. Apart from contributing to general small mammal studies in Africa, the present study may have implications in epidemiological, agricultural, biological conservation, and invasion biology research associated with cryptic invasive rodents. It is unlikely that it is only in South Africa that the presence of $R$. tanezumi has been obscured because of its morphological similarity to $R$. rattus. Genetic monitoring was crucial for detecting this cryptic invasive species that silently became established throughout much of the established range of competing congeners, and is an approach that should be considered in all areas to which members of the $R$. rattus species complex have been introduced.

\section{Additional material}

Additional file 1: Table S1: Eigenvectors from first three principal components (PC) analysis of eight bioclimatic variables in 134 native and 13 invasive records of occurrence.

Additional file 2: Figure S2: Median-joining networks of cytochrome $b$ (cyt $b$ ) haplotypes for each of the three Rattus species in South Africa (a) Rattus tanezumi (full-length), (b) Rattus rattus (full-length). The circle size of South African Rattus haplotypes is proportional to the frequency of the haplotype. Haplotype colour coding is consistent with that used in Figure 1, viz. Yellow = south Africa (This study), Green = Africa (Genbank), Grey = Outside Africa (Genbank). Each of the mutational steps separating haplotypes is indicated in blue and corresponds to the relevant position in the cyt $b$ gene, whilst black nodes correspond to median vectors. Haplotype numbers are the same as those provided in Table 1.

Additional file 3: Figure S3: Neighbor-joining tree depicting R. rattus haplotype relationships inferred from a homologous $1043 \mathrm{bp}$ region of the mitochondrial cytochrome $b$ gene. Nodal support values, expressed as a percentage and $\geq 55$ are indicated next to the relevant nodes and are based on 1,000,000 bootstrap replications. The tree was rooted with $R$. tanezumi, haplotype RT01. Square brackets are used to indicate haplotypes defined in the Tollenaere et al. [4] study. The haplotypes identified on the basis of complete cyt $b$ sequence data, and assigned in this study are indicated in bold and denoted RR01-RR10. 


\section{Acknowledgements}

This work was funded in part by the Crop Protection Programme of the United Kingdom's Department for International Development (DFID) [R8190/ ZA0506] and the European Commission's INCO-DEV programme [ICA4 2002 10056/Ratzooman]. ADSB and PJT were funded by the South African National Research Foundation (NRF) and CTC by the South African Department of Science and Technology (DST)-NRF's Centre of Excellence for Invasion Biology (CIB). The views expressed in this paper are not necessarily those of DFID, EC, DST, the NRF or CIB. We wish to express our sincere thanks to Teresa Kearney of the Transvaal Museum for curatorial assistance, Mark Robertson (University of Pretoria) for advice on the Bioclimatic models and analyses, Dr. Hitoshi Suzuki (Hokkaido University) for locality information, and Drs Craig Symes (University of the Witwatersrand), Rahmini Sudarmaji (Indonesian Institute for Rice Research) and Nguyen Phu Tuan (National Institute of Plant Protection in Vietnam) for supplying Rattus norvegicus samples. We gratefully acknowledge the reviewer comments and discussions with Drs Ken Aplin and Dan Haydon which greatly improved the manuscript and all field assistance obtained with trapping and collection of tissue samples for this study.

\section{Author details}

'Mammal Research Institute, Department of Zoology and Entomology, University of Pretoria, Private Bag 20, Hatfield 0028, Pretoria, South Africa. ${ }^{2}$ DST-NRF Centre of Excellence for Invasion Biology (CIB), Department of Zoology \& Entomology, University of Pretoria, Pretoria 0002, South Africa. ${ }^{3}$ School of Biological and Conservation Sciences, University of KwaZulu-Natal, University Road, Westville, KwaZulu-Natal, 3629, South Africa. ${ }^{4}$ Department of Ecology \& Resource Management, School of Environmental Sciences, University of Venda, P/Bag X5050, Thohoyandou 0950, South Africa. ${ }^{5}$ ARCPlant Protection Research Institute, Private Bag X134, Queenswood 0121, South Africa. ${ }^{6}$ Resource Ecology Group, Wageningen University, Droevendaalsesteeg 3a, 6708 PB Wageningen, The Netherlands. ${ }^{7}$ Natural Resources Institute, University of Greenwich, Kent ME4 4TB, UK.

\section{Authors' contributions}

Sample and field data collection: FK, EvM, PJT. Nucleotide sequence data generation: ADSB, HB, DN, MEM, JML, SD. Molecular analyses: ADSB, PvH. Karyotyping: DN, GC. GIS analyses: PJT. Drafted the manuscript: ADSB. All authors read, approved and contributed to the manuscript.

\section{Competing interests}

The authors declare that they have no competing interests.

Received: 20 September 2010 Accepted: 16 February 2011 Published: 16 February 2011

\section{References}

1. Aplin KP, Chesser T, ten Have J: Evolutionary biology of the genus Rattus: profile of an archetypal rodent pest. In Rats, Mice and People: Rodent Biology and Management. Edited by: Singleton GR, Hinds LA, Krebs CJ, Spratt DM. Canberra: The Australian Centre for International Agricultural Research (ACIAR); 2003:487-498

2. Schlick NE, Jensen-Seaman MI, Orlebeke K, Kwitek AE, Jacob HJ, Lazar J: Sequence analysis of the complete mitochondrial DNA in 10 commonly used inbred rat strains. American J Physiol Cell Physiol 2006, 291 C1183-C1192.

3. Matisoo-Smith E, Robins J: Mitochondrial DNA evidence for the spread of Pacific rats through Oceania. Biological Invasions 2009, 11:1521-1527.

4. Tollenaere C, Brouat C, Duplantier J-M, Rahalison L, Rahelinirina S, Pascal M, Moné H, Mouahid G, Leirs H, Cosson J-F: Phylogeography of the introduced species Rattus rattus in the western Indian Ocean, with special emphasis on the colonization history of Madagascar. J Biogeogr 2010, 37:398-410.

5. Meerburg BG, Singleton GR, Kijlstra A: Rodent-borne diseases and their risks for public health. Critical Rev Microbiol 2009, 35:221-270.

6. de Bruyn PJN, Bastos ADS, Eadie C, Tosh CA, Bester MN: Mass mortality of adult male sub Antarctic fur seals: Are alien mice the culprits? PLoS One 2008, 3(11):e3757.

7. Wyatt KB, Campos PF, Gilbert MTP, Kolokotronis S-O, Hynes WH, deSalle R, Daszak P, MacPhee RDE, Greenwood AD: Historical mammal extinction on
Christmas Island (Indian Ocean) correlates with introduced infectious disease. PloS One 2008, 3(11):e3602.

8. Pagès $M$, Chaval $Y$, Herbreteau V, Waengsothorn $S$, Cosson J-F, Hugot J-P, Morand S, Michaux J: Revisiting the taxonomy of the Rattini tribe: a phylogeny-based delimitation of species boundaries. BMC Evol Biol 2010, 10:184.

9. Robins JH, McLenachan PA, Phillips MJ, Craig L, Ross HA, Matisoo-Smith E: Dating of divergences within the Rattus genus phylogeny using whole mitochondrial genomes. Mol Phylogenet Evol 2008, 49:460-466.

10. Matisoo-Smith E, Robins J: Origins and dispersals of Pacific peoples: evidence from mtDNA phylogenies of the Pacific rat. Proc Nat Acad Sci USA 2004, 101:9167-9172.

11. Abhyankar A, Park H-B, Tonolo G, Luthman H: Comparative sequence analysis of the non-protein-coding mitochondrial DNA of inbred rat strains. PLoS One 2009, 4(12):e8148.

12. Musser GG, Carleton MD: Family Muridae. In Mammal species of the world: a taxonomic and geographic reference. Edited by: Wilson DE, Reeder. Baltimore: John Hopkins University Press; 2005:894-1531.

13. Robins $\mathrm{JH}$, Hingston M, Matisoo-Smith E, Ross H: Identifying Rattus species using small fragments of mitochondrial DNA: a barcoding approach. Mol Ecol Notes 2007, 7:717-729.

14. Skinner JD, Chimimba CT: The mammals of the southern African subregion. Cape Town: Cambridge University Press; 32005.

15. Colangelo P, Granjon L, Taylor PJ, Corti M: Evolutionary systematics in African gerbilline rodents of the genus Gerbilliscus: inference from mitochondrial genes. Mol Phylogenet Evol 2007, 42:797-806.

16. Venturi FP, Chimimba CT, van Aarde RJ, Fairall N: The distribution of two medically important cryptic rodent species, Mastomys natalensis and $M$. coucha (Rodentia: Muridae) in South Africa. African Zoology 2004, 39:235-245.

17. Taylor PJ, Arntzen L, Hayter M, lles M, Frean J, Belmain S: Understanding and managing sanitary risks due to rodent zoonoses in an African city: beyond the Boston Model. Integrative Zool 2008, 3:38-50.

18. Leirs H: Management of rodents in crops: The Pied Piper and his orchestra. In Rats, Mice and People: Rodent Biology and Management. Edited by: Singleton GR, Hinds LA, Krebs CJ, Spratt DM. Canberra: The Australian Centre for International Agricultural Research (ACIAR); 2003:180-190.

19. Lecompte E, Brouat C, Duplantier U-M, Galan M, Granjon L, Louiseau A, Mouline K, Cosson J-F: Molecular identification of four cryptic species of Mastomys (Rodentia, Murinae). Biochem Systematics Ecol 2005, 33:681-689.

20. Russo IR, Chimimba CT, Bloomer P: Mitochondrial DNA differentiation between two species of Aethomys (Rodentia: Muridae) from southern Africa. J Mammal 2006, 87:545-553.

21. Bastos ADS, Chimimba CT, von Maltitz E, Kirsten F, Belmain S: Identification of rodent species that play a role in disease transmission to humans in South Africa. Proceedings of the South African Society for Veterinary Epidemiology and Preventive Medicine 2005, 78-83.

22. Skinner JD, Smithers RHN: The mammals of the southern African subregion. Pretoria: University of Pretoria; 21990.

23. Tamura K, Dudley J, Nei M, Kumar S: MEGA4: Molecular Evolutionary Genetics Analysis (MEGA) software version 4.0. Mol Biol Evol 2007, 24:1596-1599

24. Posada D, Crandall KA: Modeltest: Testing the model of DNA substitution. Bioinformatics 1998, 14:817-818

25. Guidon S, Gascuel O: A simple, fast and accurate algorithm to estimate large phylogenies by maximum likelihood. Syst Biol 2003, 52:696-704.

26. Huelsenbeck JP, Ronquist F: MrBayes: Bayesian inference of phylogeny. Bioinformatics 2001, 17:754-755.

27. Suzuki H, Tsuchiya K, Takezaki N: A molecular phylogenetic framework for the Ryukyu endemic rodents Tokudaia osimensis and Diplothrix legata. Mol Phylogenet Evol 2000, 15:15-24.

28. Suzuki H, Sato JJ, Tsuchiya K, Luo J, Zhang Y-P, Wang Y-X, Jiang X-L: Molecular phylogeny of wood mice (Apodermus, Muridae) in East Asia. Biol J Linn Soc 2003, 80:469-481.

29. Chinen AA, Suzuki H, Aplin KP, Tsuchiya K, Suzuki S: Preliminary genetic characterization of two lineages of black rats (Rattus rattus sensu lato) in Japan, with evidence for introgression at several localities. Genes Genet Syst 2005, 80:367-375.

30. Truong TT, Yoshimatsu K, Araki K, Lee B-H, Nakamura I, Endo R, Shimizu K, Yasuda SP, Koma T, Taruishi M, Okumura M, Truong UN, Arikawa J: 
Molecular epidemiological and serological studies of Hantavirus infection in Northern Vietnam. J Vet Med Sci 2009, 71:1357-1362.

31. Librado P, Rozas J: DnaSP v5: A software for comprehensive analysis of DNA polymorphism data. Bioinformatics 2009, 25:1451-1452.

32. Bandelt $\mathrm{H}$-J, Forster $\mathrm{P}$, Rohl A: Median-joining networks for inferring intraspecific phylogenies. Mol Biol Evol 1999, 16:37-48.

33. Hingston M, Goodman SM, Ganzhorn JU, Sommer S: Reconstruction of the colonization of southern Madagascar by introduced Rattus rattus. J Biogeogr 2005, 32:1549-1559.

34. Hsu TC, Patton JL: Bone marrow preparation for chromosomes studies. In Comparative Mammalian Cytogenetics. Edited by: Benirschke K. Berlin: Springer; 1969:454-460.

35. Contrafatto G, Meester JA, Bronner G, Taylor PJ, Willan K: Genetic variation in the African rodent sub-family Otomyinae (Muridae): IV: Chromosome G-banding analysis of Otomys irroratus and O. angoniensis. Israel J Zool 1999, 38:277-291.

36. Yosida TH: Chromosomal and biochemical evolution in the genus Rattus. Acta Zool Fenn 1985, 170:7-14.

37. Mau-Crimmins TM, Schussman HR, Geiger EL: Can the invaded range of a species be predicted sufficiently using only native-range data? Lehmann lovegrass (Eragrostis lehmanniana) in the southwestern United States. Ecological Modelling 2006, 193:736-746.

38. Ficetola GF, Thuiller W, Miaud C: Prediction and validation of the potential global distribution of a problematic alien invasive species the American bullfrog. Diversity Distributions 2007, 13:476-485.

39. Fitzpatrick MC, Weltzin JF, Sanders NJ, Dunn RR: The biogeography of prediction error: why does the introduced range of the fire ant overpredict its native range? Global Ecol Biogeogr 2007, 16:24-33.

40. Beaumont LJ, Gallagher RV, Thuiller W, Downey PO, Leishman MR, Hughes $L$ : Different climatic envelopes among invasive populations may lead to underestimations of current and future biological invasions. Diversity and Distributions 2009, 15:409-420.

41. Hijmans RJ, Cameron SE, Parra JL, Jones PG, Jarvis A: Very high resolution interpolated climate surfaces for global land areas. Int I Climatol 2005, 25:1965-1978.

42. Sanderson EW, Jaiteh M, Levy MA, Redford KH, Wannebo AV, Woolmer G: The human footprint and the last of the wild. BioScience 2002, 52:891-904.

43. Phillips SJ, Anderson RP, Schapire RE: Maximum entropy modeling of species geographic distributions. Ecological Modelling 2006, 190:231-259.

44. Elith J, Graham CH, Anderson RP, et al: Novel methods improve prediction of species' distributions from occurrence data. Ecography 2006, 29:129-151.

45. Yosida TH, Kato H, Tsuchiya K, Sagai T, Moriwaki K: Cytogenetical survey of black rats, Rattus rattus, in Southwest and Central Asia, with special regard to the evolutional relationship between three geographical types. Chromosoma 1974, 45:99-109.

46. Gibbs RA, Weinstock GM, Metzker ML, et al: Genome sequence of the brown Norway rat yields insights into mammalian evolution. Nature 2004, 428:492-521.

47. Nilsson MA, Gullberg A, Spotorno AE, Arnason U, Janke A: Radiation of extant marsupials after the $\mathrm{K} / \mathrm{T}$ boundary: evidence from complete mitochondrial genomes. J Mol Evol 2003, 57(Suppl 1):S3-S12.

48. Serizawa K, Suzuki H, Tsuchiya K: A phylogenetic view on species radiation in Apodemus inferred from variation of nuclear and mitochondrial genes. Biochem Genet 2000, 38:27-40.

49. Gadaleta G, Pepe G, De Candia G, Quagliariello C, Sbisa E, Saccone C: The complete nucleotide sequence of the Rattus norvegicus mitochondrial genome: cryptic signals revealed by comparative analysis between vertebrates. J Mol Evol 1989, 28:497-516.

doi:10.1186/1471-2156-12-26

Cite this article as: Bastos et al.: Genetic monitoring detects an overlooked cryptic species and reveals the diversity and distribution of three invasive Rattus congeners in South Africa. BMC Genetics 2011 12:26.

\section{Submit your next manuscript to BioMed Central and take full advantage of:}

- Convenient online submission

- Thorough peer review

- No space constraints or color figure charges

- Immediate publication on acceptance

- Inclusion in PubMed, CAS, Scopus and Google Scholar

- Research which is freely available for redistribution

Submit your manuscript at www.biomedcentral.com/submit 